\title{
Sexual dysfunction due to pudendal neuralgia: a systematic review
}

\author{
Fouad Aoun ${ }^{1,2} \wedge$, Marwan Alkassis ${ }^{1}$, Georges Abi Tayeh $^{1} \wedge$, Josselin Abi Chebel ${ }^{1}$, Albert Semaan ${ }^{1}$, \\ Julien Sarkis ${ }^{1} \wedge$, Raymond Mansour ${ }^{1}$, Georges Mjaess ${ }^{1,3} \wedge$, Simone Albisinni ${ }^{3} \wedge$, Fabienne Absil ${ }^{4}$, \\ Renaud Bollens ${ }^{5}$, Thierry Roumeguère ${ }^{2,3 \wedge}$
}

${ }^{1}$ Urology Department, Hôtel Dieu de France, Université Saint Joseph, Beirut, Lebanon; ${ }^{2}$ Urology Department, Institut Jules Bordet, Université Libre de Bruxelles, Brussels, Belgium; ${ }^{3}$ Urology Department, Cliniques Universitaires de Bruxelles, Hôpital Erasme, Université Libre de Bruxelles, Brussels, Belgium; ${ }^{4}$ Urology department, Centre Hospitalier EpiCURA, Site de Ath, Ath, Belgium; ${ }^{5}$ Urology department, Centre Hospitalier de Wallonie Picarde, Tournai, Belgium

Contributions: (I) Conception and design: F Aoun, G Mjaess, R Bollens, T Roumeguère; (II) Administrative support: F Aoun, R Bollens, T Roumeguère; (III) Provision of study materials or patients: M Alkassis, GA Tayeh; (IV) Collection and assembly of data: F Aoun, M Alkassis, GA Tayeh; (V) Data analysis and interpretation: F Aoun, M Alkassis, GA Tayeh, A Semaan, JA Chebel, J Sarkis, R Mansour, G Mjaess; (VI) Manuscript writing: All authors; (VII) Final approval of manuscript: All authors.

Correspondence to: Fouad Aoun, MD, MSc. Urology Department, Institut Jules Bordet, Université Libre de Bruxelles, Belgium.

Email: fouad.aoun@bordet.be.

\begin{abstract}
Background: The pudendal nerve is considered as the main nerve of sexuality. Pudendal neuralgia is an underdiagnosed disease in clinical practice. The aim of this systematic review is to highlight the role of pudendal neuralgia on sexual dysfunction in both sexes.

Methods: A PubMed search was performed using the following keywords: "Pudendal" AND "Sexual dysfunction" or "Erectile dysfunction" or "Ejaculation" or "Persistent sexual arousal" or "Dyspareunia" or "Vulvodynia". The search involved patients having sexual dysfunction due to pudendal neuralgia. Treatment received was also reported.

Results: Five case series, seven cohort studies, two pilot studies, and three randomized clinical trials were included in this systematic review. Pudendal nerve and/or artery entrapment, or pudendal neuralgia, is a reversible cause of multiple sexual dysfunctions. Interventions such as anesthetic injections, neurolysis, and decompression are reported as potential treatment modalities. There are no studies describing the role of pudendal canal syndrome in the pathophysiology or treatment of delayed ejaculation or penile shortening.

Discussion: Pudendal neuralgia is an underestimated yet important cause of persistent genital arousal, erectile dysfunction (ED), premature ejaculation (PE), ejaculation pain, and vulvodynia. Physicians should be aware of this entity and examine the pudendal canal in such patients before concluding an idiopathic cause of sexual dysfunction.
\end{abstract}

Keywords: Pudendal nerve; sexual dysfunction; erectile dysfunction (ED); ejaculation; sexuality

Submitted Aug 14, 2020. Accepted for publication Jan 26, 2021.

doi: $10.21037 /$ tau-21-13

View this article at: http://dx.doi.org/10.21037/tau-21-13

$\wedge$ ORCID: Fouad Aoun, 0000-0002-8291-4302; Marwan Alkassis, 0000-0002-8203-7952; Georges Abi Tayeh, 0000-0003-3179-1290; Albert Semaan, 0000-0001-8915-5970; Julien Sarkis, 0000-0002-5060-0819; Georges Mjaess, 0000-0002-8703-4611; Simone Albisinni, 00000001-5529-3064; Thierry Roumeguère, 0000-0002-5377-8137. 


\section{Introduction}

Normal sexual function in males necessitates libido, initiating and maintaining erection, orgasm, ejaculation, and refractory period (1). Normal sexual function in females includes swelling of the clitoris and labia minora, vaginal lubrication and lengthening, nipple erection, increased genital sensitivity during the arousal and plateau phases, followed by the orgasm (2). Sexual response involves social, psychological, neurological, vascular, and hormonal processes and is based on both psychological as well as local sexual stimulation, the central nervous system, the peripheral neurovascular system, and hormonal influences $(3,4)$. Sexual dysfunctions include persistent genital arousal disorder (PGAD), dyspareunia and vulvodynia, and male erectile and ejaculation dysfunction. Many factors contribute to sexual dysfunction in both sexes.

Recently, attention toward the pudendal nerve and artery entrapment as a cause of sexual dysfunction has grown (5). Two recent studies have shown that penile numbness and erectile dysfunction (ED) could be related to pelvic discomfort and pudendal nerve compression without neuropathic pain especially among cyclists $(5,6)$. Another study demonstrated that persistent sexual arousal could be due to a minimal degree of chronic compression of the dorsal branch of the pudendal nerve (7). Other two recent pilot studies have shown beneficial effect of pudendal nerve and artery decompression on ED and computed-guided pudendal nerve block on PE $(8,9)$. The aim of our systematic review is to highlight the role of pudendal neuralgia on sexual function in both sexes. We present the following article in accordance with the PRISMA reporting checklist (available at http://dx.doi.org/10.21037/tau-21-13).

\section{Methods}

\section{Strategy of research}

Research was performed in March 2020, using PubMed database. No research filters were used. Keywords used were: "Pudendal" AND "Sexual dysfunction" or "Erectile dysfunction" or "Ejaculation" or "Persistent sexual arousal" or "Dyspareunia" or "Vulvodynia".

\section{Selection of articles}

The selection procedure followed the Preferred Reporting Items for Systematic Reviews and Meta-analysis (PRISMA) principles and is presented using a PRISMA flow chart.
Although recent articles were prioritized, manuscripts with relevant historical findings were referenced as well. Evidence included human, animal and cadaver data. Each article's title, abstract and text were reviewed for their appropriateness and their relevance. The initial list of selected papers was enriched by individual suggestions of the authors of the present review. After duplicate removal, titles and abstracts were checked for relevance by two reviewers (MA, GAT). Full text analysis of eligible studies was performed by three reviewers (MA, GAT, and FA).

\section{Extraction of data}

Collection of data was done by two authors (MA, GAT). Data were grouped depending on the type of clinical studies. Outcomes were all sexual disorders which were mentioned to be caused by pudendal canal entrapment or neuralgia, and any treatment suggested for every condition.

\section{Results}

Seventeen clinical studies (five case series, seven cohort studies, two pilot studies and three randomized clinical trials) were included in our review. PRISMA flow chart is presented in Figure 1. All these studies have reported the role of compression of the pudendal nerve and/or the pudendal artery in the pathophysiology and treatment of sexual dysfunction.

One case series and one cohort study dealt with PGAD. The case series evaluated the efficacy of chronic pudendal neuromodulation as a treatment for PGAD. Results were promising as three out of four patients who completed the surveys, reported relief of their symptoms (10). The cohort study reported the efficacy of neurolysis of the dorsal branch of the pudendal nerve for PGAD in eight women (7). The seven patients who were operated bilaterally reported complete response, while the only patient operated unilaterally reported partial response.

The relationship between ED and pudendal canal entrapment was less studied until recently. Two case series, one cohort study and one pilot study dealt with ED. A case series evaluated the efficacy of pudendal canal decompression in treating neurogenic ED due to pudendal nerve entrapment, as six out of seven patients reported total potency after six months of follow-up (11). In the second case series, ten patients with ED were operated with a pudendal canal decompression. While all six patients who suffered from isolated 


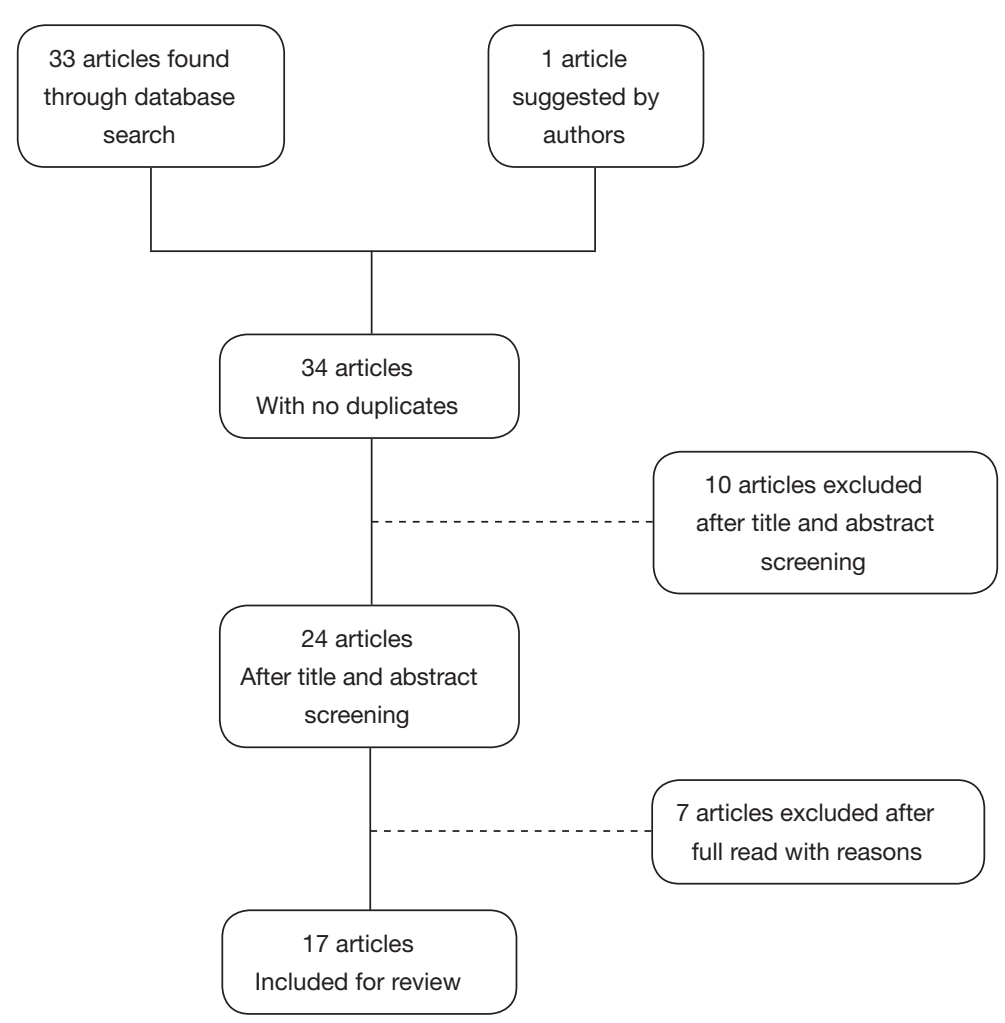

Figure 1 PRISMA flow chart of the study.

arteriogenic ED reported improvement of their symptoms, only two out of four patients who suffered from combined arteriogenic and neurogenic ED reported satisfactory results (12). One cohort study evaluated multiple sexual dysfunctions in seven men with a compression of the dorsal branch of the pudendal nerve. Unilateral and bilateral neurolysis and decompression yielded satisfactory results in all sexual symptoms, including ED (13). Recently in a pilot study, we have reported improvement of erectile function in five healthy young males presenting with refractory ED after laparoscopic transperitoneal pudendal nerve and artery release (8), which is considered a safe and efficacious technique to decompress the pudendal canal (14).

Two case series, three cohort studies, one pilot study, and one randomized clinical trial dealt with premature ejaculation (PE). The first case series evaluated the efficacy of penile dorsal nerve neuromodulation as a treatment for $\mathrm{PE}$ in fifteen patients. After a follow-up of three weeks, the intravaginal ejaculatory latency time (IELT) and the sexual satisfaction score (SSS) were significantly increased $(\mathrm{P}<0.05)$ in all patients (15). The second case series demonstrated the efficacy of neurotomy of branches of the dorsal nerve in nineteen patients with PE (16). Seventy-nine percent of the patients reported significant improvement of the average ejaculation latency and the coitus satisfaction degree. Three cohort studies reported the efficacy of penile dorsal nerve resection as a treatment for $\mathrm{PE}$. The first cohort study described a total efficacy rate of $92 \%$ in the 483 patients treated with resection of the dorsal penile nerve after 36 months of follow-up (17). The second cohort study reported less satisfactory results as $75 \%$ of 146 patients were satisfied with this surgical treatment (18). As for the third cohort study, 330 patients with primary PE were treated with penile dorsal nerve rhizotomy. Satisfactory results were noted in $95 \%$ of the patients (19). We have recently reported in a pilot study the improvement of $\mathrm{PE}$ in $5 / 5$ of patients, after computed-guided pudendal nerve block using local anesthetics and steroids (9). One randomized clinical trial compared the efficacy of dorsal penile nerve amputation with alpha adrenergic receptor blocker to each treatment alone, as a treatment for PE. The results were significantly in favor of the combined therapy (20).

Two cohort studies and two randomized clinical trials dealt with vestibulodynia. The first cohort study proved the efficacy of pudendal nerve block with infiltration of local anesthetic agents among other treatments, as a treatment 
for provoked vestibulodynia in 27 women (21). The second cohort study discussed the role of transcutaneous electrical nerve stimulation (TENS) as a treatment for resistant provoked vulvodynia in 39 women (22). The efficacy of this therapeutic modality was noted immediately and after a follow-up of 10 months, and only $4 \%$ of the patients needed additional therapy such as vestibulectomy. A double-arm randomized controlled trial demonstrated the efficacy of the TENS as a treatment for vestibulodynia as it proved its significant superiority compared to placebo, after twenty treatment sessions (23). In fact, the visual analogue score the McGill-Melzack Pain Questionnaire scores significantly improved in the active TENS group $(6.2 \pm 1.9$ and $19.5 \pm 11.9$ before treatment, respectively; to $2.1 \pm 2.7, \mathrm{P}=0.004$ and $8.5 \pm 10.7, \mathrm{P}=0.001$, respectively) but not in the placebo group. The other double-arm randomized controlled trial compared the efficacy of intravaginal diazepam and TENS versus placebo and TENS for the treatment of vestibulodynia (24). The visual analogue scale did not show significant difference between the two groups; however, the Marinoff dyspareunia scale was significantly in favor of the diazepam group.

No study dealing with the role of pudendal neuralgia and ejaculatory pain was found in the literature.

Table 1 summarizes the results of our systematic review.

\section{Discussion}

\section{Anatomy}

The pudendal nerve carries autonomic, sensory and motor fibers to the anal, perineal and genital region $(25,26)$. One of its branches, the dorsal nerve of the penis or clitoris, supplies erectile tissue of the corpus cavernosum and the crus penis/clitoris, as well as the skin over the dorsal and lateral aspect of penis and clitoris (26). Although largely made up of somatic sensory nerves-which play a major role during sexual activity - the dorsal nerve of the penis also includes nNOS-containing fibers (27); this means that this nerve regulates erectile and ejaculatory functions. In fact, somatomotor fibers from the Onuf's nucleus innervate via the pudendal nerve (through sacral plexus) the ischiocavernosus and bulbocavernosus muscles. Contraction of the ischiocavernosus muscles produces the rigiderection phase. Repeated contraction and compression of the bulbocavernosus muscle on the proximal corpus is also responsible for the ejection phase of ejaculation (28).

The primary source of penile blood is the paired internal pudendal arteries, which are branches of the internal iliac arteries. The internal pudendal artery becomes the common penile artery that gives three branches. The cavernous artery effects tumescence of the corpus cavernosum and gives helicine arteries along its course; these arteries supply the trabecular erectile tissue and the sinusoids and are contracted and tortuous in the flaccid state. During erection, they become dilated and straight, by dint of the dorsal artery of the penis which is responsible for the glans engorgement. The bulbourethral artery supplies the proximally located penile bulb and corpus spongiosum (29). As in male, the female sexual reflex uses the somatic pudendal nerve afferents; parasympathetic stimulation causes dilation of dorsal and deep arteries of the clitoris, thus leading to clitoral engorgement (30).

The pudendal nerve passes between two muscles, piriformis and coccygeus muscles (31), and exits the pelvis via the infra-piriform notch of the greater sciatic foramen anterior to the sciatic nerve and the sacrotuberous ligament. At the level of the ischial spine, it passes medial to and below the sacrospinous ligament and returns to the pelvis via the lesser sciatic foramen. It then passes within a canal - the pudendal canal or Alcock canal - formed by a duplication of the obturator internus fascia $(26,31)$. Given this complex anatomical passage, the pudendal nerve is subject to compression at different levels: below the piriformis muscle, between the sacrospinous and sacrotuberous ligaments in the Alcock canal, and entrapment of terminal branches $(25,31)$. The prevalence of pudendal nerve entrapment is certainly underestimated (32).

Nerve entrapment or injury can occur due to pelvic surgery, most commonly repair of pelvic organ prolapse especially with placement of a mesh. Mid-urethral sling surgeries, hysterectomies and anterior colporrhaphy are also surgeries that put the pudendal nerve at risk of injury. The pudendal nerve may also be compromised by inflammation due to herpes simplex infection or pelvic tumoral compression or chemoradiation. Direct gluteal or back trauma, vaginal delivery, chronic constipation, excessive cycling and prolonged sitting all predispose to pudendal nerve injury as well (33-38).

\section{$P G A D$}

PGAD is a newly discovered entity in female and male sexuality that includes the following features: (I) sexual arousal extending in time and not subsiding on its own, (II) sexual arousal not relieved by ordinary orgasm and 
Table 1 Summary of results of our systematic review

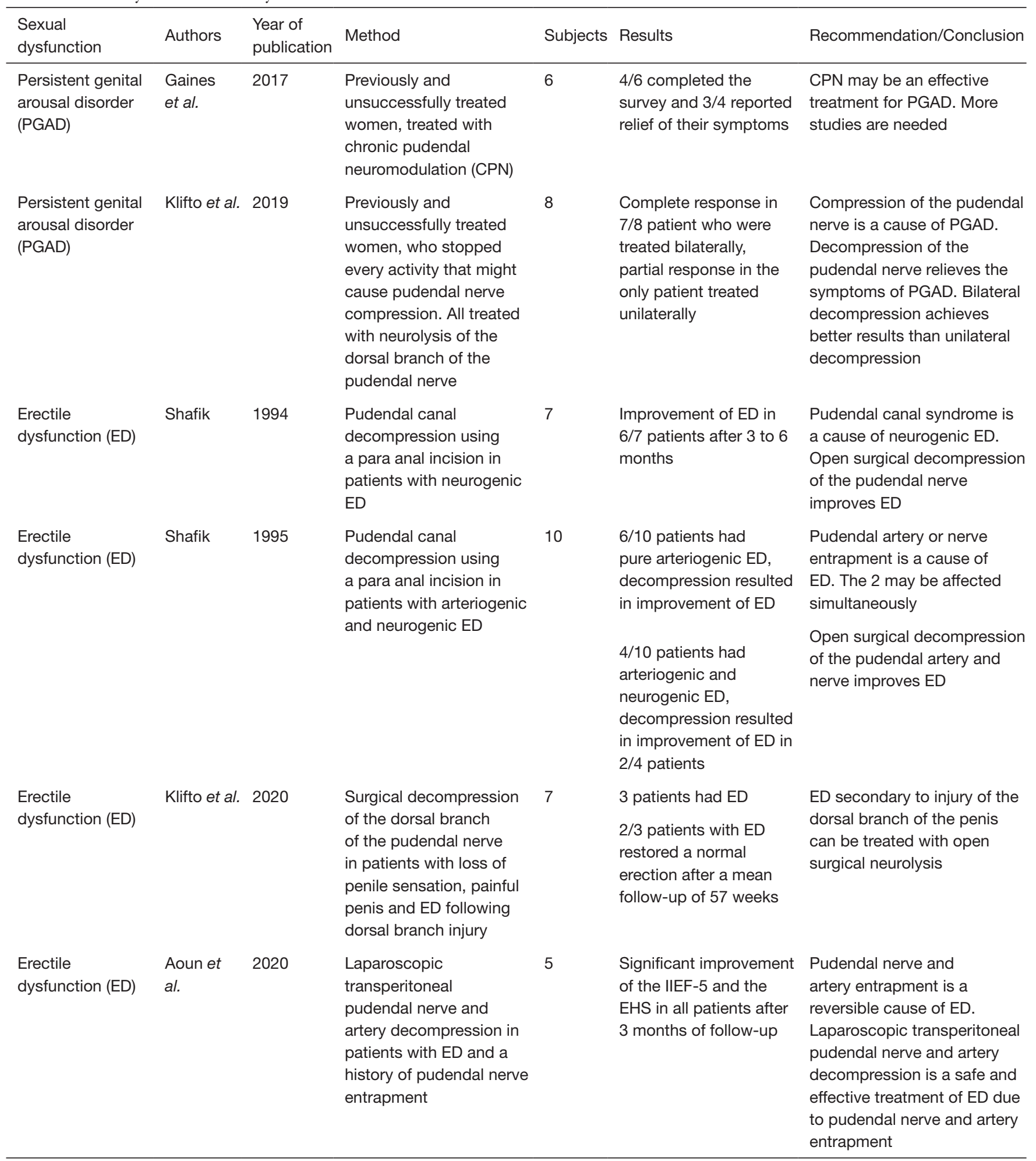

Table 1 (continued) 
Table 1 (continued)

\begin{tabular}{|c|c|c|c|c|c|c|}
\hline $\begin{array}{l}\text { Sexual } \\
\text { dysfunction }\end{array}$ & Authors & $\begin{array}{l}\text { Year of } \\
\text { publication }\end{array}$ & Method & Subjects & Results & Recommendation/Conclusion \\
\hline $\begin{array}{l}\text { Premature } \\
\text { ejaculation (PE) }\end{array}$ & $\begin{array}{l}\text { Basal } \\
\text { et al. }\end{array}$ & 2010 & $\begin{array}{l}\text { PRF neuromodulation of } \\
\text { the dorsal penile nerves } \\
\text { in patient with PE (without } \\
\text { ED) that was resistant to } \\
\text { conventional treatments }\end{array}$ & 15 & $\begin{array}{l}\text { Significant increase of } \\
\text { the IELT and the SSS } \\
\text { after } 3 \text { weeks of the } \\
\text { procedure in all patients }\end{array}$ & $\begin{array}{l}\text { PRF is an effective treatment } \\
\text { of PE yet placebo controlled } \\
\text { studies and objective tools } \\
\text { are needed }\end{array}$ \\
\hline $\begin{array}{l}\text { Premature } \\
\text { ejaculation (PE) }\end{array}$ & $\begin{array}{l}\text { Zhang } \\
\text { et al. }\end{array}$ & 2012 & $\begin{array}{l}\text { Penile dorsal nerve } \\
\text { neurotomy for PE, by } \\
\text { maintaining only two } \\
\text { branches }\end{array}$ & 146 & $\begin{array}{l}\text { Objective assessment } \\
\text { using the VPT test } \\
75 / 146 \text { cured } \\
34 / 146 \text { improved } \\
37 / 146 \text { ineffective } \\
\text { Total effective rate of } \\
75 \%\end{array}$ & $\begin{array}{l}\text { VPT is a non-invasive, } \\
\text { objective, and safe approach } \\
\text { for dorsal penile nerve } \\
\text { sensory detection. Penile } \\
\text { dorsal nerve neurotomy can } \\
\text { be applied for treating PE }\end{array}$ \\
\hline $\begin{array}{l}\text { Premature } \\
\text { ejaculation (PE) }\end{array}$ & $\begin{array}{l}\text { Aoun } \\
\text { et al. }\end{array}$ & 2020 & $\begin{array}{l}\text { CT-guided pudendal } \\
\text { nerve block at the } \\
\text { sacrospinous ligament } \\
\text { and the Alcock's canal } \\
\text { with ropivacaine and } \\
\text { methylprednisone }\end{array}$ & 5 & $\begin{array}{l}\text { IELT, IIEF-5, PEDT and } \\
\text { SQol-M questionnaire } \\
\text { significantly improved } \\
\text { after treatment }\end{array}$ & $\begin{array}{l}\text { CT-guided pudendal nerve } \\
\text { block at the sacrospinous } \\
\text { ligament and the Alcock's } \\
\text { canal is an effective treatment } \\
\text { for sensory PE }\end{array}$ \\
\hline
\end{tabular}

Table 1 (continued) 
Table 1 (continued)

\begin{tabular}{|c|c|c|c|c|c|c|}
\hline $\begin{array}{l}\text { Sexual } \\
\text { dysfunction }\end{array}$ & Authors & $\begin{array}{l}\text { Year of } \\
\text { publication }\end{array}$ & Method & Subjects & Results & Recommendation/Conclusion \\
\hline $\begin{array}{l}\text { Premature } \\
\text { ejaculation (PE) }\end{array}$ & $\begin{array}{l}\text { Jian-hua } \\
\text { et al. }\end{array}$ & 2012 & $\begin{array}{l}3 \text { groups: -selective } \alpha 1 \text { - } \\
\text { adrenergic receptor } \\
\text { blocker } \\
\text {-dorsal penile nerve } \\
\text { amputation surgery } \\
\text {-combination therapy }\end{array}$ & 89 & $\begin{array}{l}\text { IELT was significantly } \\
\text { improved in the } \\
\text { combination therapy } \\
\text { group compared to the } \\
\text { other groups }\end{array}$ & $\begin{array}{l}\text { Dorsal penile nerve } \\
\text { amputation surgery combined } \\
\text { with } \alpha 1 \text {-adrenergic receptor } \\
\text { blocker is an effective } \\
\text { treatment for PE }\end{array}$ \\
\hline Vestibulodynia & $\begin{array}{l}\text { Rapkin } \\
\text { et al. }\end{array}$ & 2008 & $\begin{array}{l}\text { Five sessions of caudal } \\
\text { epidural, pudendal nerve } \\
\text { block, and vestibular } \\
\text { infiltration of local } \\
\text { anesthetic agents }\end{array}$ & 27 & $\begin{array}{l}\text { Vulvalgesiometer } \\
\text { (objective measure): } \\
\text { improvement in pain } \\
\text { threshold }(41 \%) \text { and } \\
\text { tolerance }(51 \%) \\
\text { Self-report questions } \\
\text { (subjective measure): } \\
57 \% \text { improvement } \\
\text { Postmenopausal women } \\
\text { less improvement than } \\
\text { premenopausal women }\end{array}$ & $\begin{array}{l}\text { Nerve block for vulvar } \\
\text { vestibulitis is effective. } \\
\text { Placebo-controlled study is } \\
\text { needed }\end{array}$ \\
\hline Vestibulodynia & $\begin{array}{l}\text { Vallinga } \\
\text { et al. }\end{array}$ & 2015 & $\begin{array}{l}\text { TENS was used for PVD. } \\
\text { Assessment with self- } \\
\text { report questionnaires and } \\
\text { visual analog scales at } \\
\text { baseline (T1), post-TENS } \\
\text { (T2), and follow-up (T3) }\end{array}$ & 39 & $\begin{array}{l}\text { Vulvar pain at T2 and T3 } \\
\text { significantly lower than } \\
\text { at baseline } \\
\text { Sexual functioning } \\
\text { scores and sexually- } \\
\text { related personal distress } \\
\text { scores had significantly } \\
\text { improved post TENS }\end{array}$ & $\begin{array}{l}\text { TENS is a feasible and } \\
\text { effective treatment for } \\
\text { therapy-resistant TENS. } \\
\text { TENS reduced the need for } \\
\text { vestibulectomy }\end{array}$ \\
\hline Vestibulodynia & $\begin{array}{l}\text { Murina } \\
\text { et al. }\end{array}$ & 2018 & $\begin{array}{l}\text { RCT: vagianal diazepam + } \\
\text { TENS vs. placebo + TENS } \\
\text { for vestibulodynia }\end{array}$ & 42 & $\begin{array}{l}\text { The VAS score } \\
\text { significantly decreased } \\
\text { in the two groups } \\
\text { The Marinoff } \\
\text { dyspareunia scores } \\
\text { and the ability to relax } \\
\text { the pelvic floor muscle } \\
\text { after contraction were } \\
\text { significantly greater for } \\
\text { the diazepam group vs. } \\
\text { the placebo group }\end{array}$ & $\begin{array}{l}\text { Vaginal diazepam plus TENS } \\
\text { is useful to improve pain and } \\
\text { pelvic floor muscle instability } \\
\text { in women with vestiulodynia }\end{array}$ \\
\hline
\end{tabular}

PGAD, persistent genital arousal disorder; ED, erectile dysfunction; CPN, chronic pudendal neuromodulation; IIEF-5, international Index for Erectile Function; EHS, erectile hardness score; PE, premature ejaculation; PPE, primary premature ejaculation; PRF, pulsed radiofrequency; IELT, intravaginal ejaculatory latency time; SSS, sexual satisfaction score; VPT, vibration sensory threshold; PEDT, premature ejaculation diagnostic tool; SQoL-M, Sexual Quality of Life-Male version; TENS, transcutaneous electrical nerve stimulation; PVD, provoked vestibulodynia; RCT, randomized controlled trial; VAS, visual analogue scale; SF-MPQ, McGill-Melzack pain questionnaire. 
may require multiple orgasms over hours or days to remit, (III) arousal is unrelated to sexual desire, (IV) arousal is triggered by both sexual and non-sexual stimuli, (V) arousal experienced as unbidden, intrusive and unwanted (39-41). Its pathophysiology is mainly based on neuro-vascular dysfunction, genital peripheral neuropathy and/or dysfunctional micro-vascular arterio-venous shunting (42), and it was described with chronic yeast infection, Tarlov cyst, initiation or cessation of some nervous system medications and pudendal nerve injury or compression $(10,43,44)$. There are currently no approved evidence-based guidelines or treatments for PGAD (45), but only few described cases and treatment suggestions. In fact, the serotonin and norepinephrine reuptake inhibitor (SNRI) duloxetine, the selective serotonin reuptake inhibitor (SSRI) paroxetine and benzodiazepine such as clonazepam and oxazepam proved their efficacy by providing arousal relief in some patients $(40,41,46,47)$. Physical therapy might release the impinged pudendal nerve by mobilizing some muscles such as the obturator internus muscle, leading to PGAD symptoms relieve (43). TENS at the pudendal dermatome may cause symptoms relief in some patients (47). Yet, noninvasive therapy is not always effective, urging the need for a more invasive therapeutic strategy. Chronic pudendal neuromodulation using an implantable pulse generator, or neurolysis of the pudendal nerve or its branches provided arousal symptoms relief in previously unsuccessfully treated patients $(7,10)$. Moreover, bilateral pudendal nerve neurolysis seems more efficacious than unilateral neurolysis (7).

While dealing with PGAD, a thorough medical history is needed and a complete physical exam is required including pudendal nerve territory examination. When there is nonevident cause of the arousal symptoms such as an infection, a palpable mass or an iatrogenic cause, we suggest to start with a noninvasive therapeutic modality (drugs, physical therapy, TENS). Pudendal nerve neuromodulation or decompression along its trajectory are used as second intention or when the medical history suggests a nerve injury or anatomical compression.

\section{$E D$}

ED is defined as the inability to achieve or maintain an erection adequate for sexual satisfaction (48). Erection is a complex physiological process which involves vascular, neural, hormonal, and structural factors (11). It entails operational cavernous nerves, a good blood flow through the internal pudendal arteries, healthy erectile tissue, and pudendal nerves capable of stimulating contraction of perineal musculature (49). ED can be caused by psychologic, neurogenic, hormonal, arterial, and venous disorders (11). Therefore, the compression of the pudendal nerve (or its ascending branches) or the pudendal artery can result in reversible ED (8,11-13). ED may be associated with modifiable and reversible conditions such as hyperlipidemia, diabetes, hypertension or certain medications side effects (antihypertensives, antidepressants, antipsychotic etc.) (50). As a result, the first step in the treatment of ED is lifestyle changes (50). Multiple therapeutic modalities exist for the treatment of ED and include oral drugs such as the phosphodiesterase type 5 inhibitors (PDE5 inhibitors), intraurethral or intracavernosal injections, vacuum device, low intensity shockwave therapy (Li-SWT) and penile prosthesis implantation (48). The choice between these treatments depends of the patient preference and the underlying pathophysiology of the ED. However, in some cases, pudendal canal entrapment syndrome may cause neurogenic and/or arteriogenic ED (11,12). Primary care doctors and surgeons should rule out this entity whenever ED is associated with other symptoms such as penile and perineal hypoesthesia, penile pain or chronic constipation (11-13). A narrow or obstructed pudendal artery on arteriography or an increase in pudendal nerve terminal motor latency might help confirming the diagnosis (12). There are no randomized control trials or evidencebased guidelines evaluating the efficacy of pudendal canal decompression. However some authors described their surgical techniques for releasing the pudendal nerve and artery and improving ED (8,11-13). Open surgical techniques using a para anal or ischiocavernosus fossa incision (11-13) or laparoscopic technique (8) succeeded in localizing the compression along the pudendal nerve or artery tract and releasing them. This resulted in improvement of ED and the associated symptoms in the majority of the patients and after a short follow-up period.

Pudendal nerve and artery entrapment is a reversible cause of ED that healthcare professionals should be aware of. Pudendal canal decompression is an easy, simple and effective treatment when performed by an experienced surgeon.

\section{$P E$}

$\mathrm{PE}$ is a male sexual dysfunction characterized by ejaculation 
that always or nearly always occurs before or within 1 minute of vaginal penetration (lifelong PE), or, a clinically significant and bothersome reduction in latency time, often to about 3 minutes or less (acquired PE), and the inability to delay ejaculation on all or nearly all vaginal penetrations, and negative personal consequences, such as distress bother, frustration, and/or the avoidance of sexual intimacy (51). PE depends on both organic and psychogenic factors (52). Diagnosis of PE depends on the patient's medical and sexual history, and a special attention should be given to the impact of $\mathrm{PE}$ on sexual activity and quality of life, the duration time of ejaculation and any form of drug abuse (53). Management of acquired $\mathrm{PE}$ relies on identifying the underlying cause (ED, urinary infection, anxiety, hyperthyroidism) and treating it accordingly (51). While management of lifelong PE depends on sexual and behavioral therapy, pharmacotherapy and procedural interventions (54). Dapoxetine and other SSRIs are used as first-line strategy for lifelong and acquired PE; topical lidocaine and prilocaine are also used (54). Procedural interventions mainly act on the pudendal nerve and its branches. In fact, PE has been recently associated with hyperexcitability of the penile dorsal nerve and a decrease in penile sensory threshold (55). Based on these findings, multiple authors have described different techniques consisting on manipulating the pudendal nerve in order to treat PE. Pulsed radiofrequency (PRF) neuromodulation of the dorsal penile nerve and CT-guided pudendal nerve block with ropivacaine and methylprednisone were used to treat patients with $\mathrm{PE}$ associated with symptoms of pudendal neuralgia $(9,15)$. These techniques yielded significant increase of the IELT and improvement of other parameters such as the SSS and the sexual quality of lifemale version (SQoL-M) $(9,15)$. More invasive surgeries such as penile dorsal nerve neurotomy and rhizotomy achieved similar satisfactory results (16-19). The combination of highly selective $\alpha 1$-adrenergic receptor blocker and penile nerve amputation yielded better results compared to each therapy alone (20), which presents a second combination strategy other than behavioral therapy and pharmacotherapy for the treatment of $\mathrm{PE}$, especially when the medical history and the physical exam suggest a pudendal canal entrapment syndrome, or simply a pudendal neuralgia. We should note that the success after pudendal block does not mean the presence of entrapment, but rather a lesion at the level of the pudendal nerve, which could be, or not, a pudendal canal entrapment.

\section{Vestibulodynia - dyspareunia}

Vulvar pain is a common symptom reported in up to $15 \%$ of women (56). Provoked vulvodynia is the leading cause of premenopausal vestibulodynia and patients tend to report a burning sensation or sharp pain upon application of vulvar pressure or attempt of vaginal penetration (57). A complex and intricate anatomy and neurophysiology help explain pathophysiologic aspects of dyspareunia and vulvodynia. In fact, the pudendal nerve, which is made up of somatic branches from the sacral plexus, is the main nervous supply of the vulva (58). In addition, the anatomic course of the pudendal nerve makes it susceptible to surgical and obstetrical trauma, potentially leading to entry dyspareunia and vulvodynia (58). It is also proposed that pelvic floor muscle dysfunction is commonly reported in women with vulvodynia. The pelvic floor muscle dysfunction places stress on the nerves running near and through these muscles, potentially explaining a pain syndrome (58). In sum, vulvodynia has a multifactorial etiology including psychogenic, functional and neuropathic factors with major implication of the pudendal nerve; which is particularly true in primary vulvodynia which usually has no known etiology (59). First-line treatments consist on local application of anesthetics like lidocaine and possibly amitriptyline, gabapentin, pregabalin (60). Moreover, due to the pudendal neve implication in the pathophysiology of vulvodynia, pudendal nerve manipulations are both diagnostic and therapeutic procedures in pudendal nerve entrapment syndromes (21-24,31). In fact, pudendal nerve block associated with vestibular infiltration of local anesthetic agents improved the objective and subjective assessment tools of vulvodynia (21). It also showed that premenopausal women have a better chance to benefit from this treatment compared to premenopausal women. TENS is another treatment modality for vulvodynia as it proved its efficacy on short and long term, as monotherapy or better combined to vaginal diazepam (22-24) and reduced the need of vestibulectomy (22).

Although this review is the first one describing the implication of pudendal neuralgia on multiple sexual symptoms, limitations include the rarity of this condition and the lack of randomized controlled trials evaluating the efficacy of the different pudendal nerve manipulations compared to the standard of care. 


\section{Conclusions}

Multiple sexual dysfunctions are labeled as idiopathic. However, despite the scarce data, attention toward the pudendal canal syndrome or pudendal neuralgia and its implication in the physiopathology of sexual dysfunction has grown. This systematic review is an invitation to every clinician to consider this syndrome when being confronted to patients with ill-defined cause resistant sexual dysfunction.

\section{Acknowledgments}

Funding: None.

\section{Footnote}

Reporting Checklist: The authors have completed the PRISMA reporting checklist. Available at http://dx.doi. org/10.21037/tau-21-13

Conflicts of Interest: All authors have completed the ICMJE uniform disclosure form (available at http://dx.doi. org/10.21037/tau-21-13). The authors have no conflicts of interest to declare.

Ethical Statement: The authors are accountable for all aspects of the work in ensuring that questions related to the accuracy or integrity of any part of the work are appropriately investigated and resolved.

Open Access Statement: This is an Open Access article distributed in accordance with the Creative Commons Attribution-NonCommercial-NoDerivs 4.0 International License (CC BY-NC-ND 4.0), which permits the noncommercial replication and distribution of the article with the strict proviso that no changes or edits are made and the original work is properly cited (including links to both the formal publication through the relevant DOI and the license). See: https://creativecommons.org/licenses/by-nc-nd/4.0/.

\section{References}

1. Mulcahy JJ, Rehman J, Melman A. Normal Anatomy and Physiology. Male Sex Funct 2003;1-46.

2. Masters WH, Johnson VE. The human female: anatomy of sexual response. Minn Med 1960;43:31-6.

3. Vignozzi L. Female sexuality: A state of mind. In: Female
Sexual Function and Dysfunction. Springer International Publishing, 2017:27-32.

4. Khonsary S. Guyton and Hall: Textbook of Medical Physiology. Vol. 8, Surgical Neurology International. 2017. 275 p.

5. Balasubramanian A, Yu J, Breyer BN, et al. The Association Between Pelvic Discomfort and Erectile Dysfunction in Adult Male Bicyclists. J Sex Med 2020;17:919-29.

6. Luther RD, Castellanos ME. Successful Treatment of Penile Numbness and Erectile Dysfunction Resulting From Pudendal Nerve Entrapment. Urology 2019;134:228-31.

7. Klifto K, Dellon AL. Persistent genital arousal disorder: Treatment by neurolysis of dorsal branch of pudendal nerve. Microsurgery 2020;40:160-6.

8. Aoun F, Mjaess G, Daher K, et al. Laparoscopic treatment of pudendal nerve and artery entrapment improves erectile dysfunction in healthy young males. Int J Impot Res 2021;33:1-5.

9. Aoun F, Mjaess G, Assaf J, et al. Clinical effect of computed guided pudendal nerve block for patients with premature ejaculation: a pilot study. Scand J Urol 2020;54:258-62.

10. Gaines N, Odom BD, Killinger KA, et al. Pudendal Neuromodulation as a Treatment for Persistent Genital Arousal Disorder-A Case Series. Female Pelvic Med Reconstr Surg 2018;24:e1-5.

11. Shafik A. Pudendal canal decompression in the treatment of erectile dysfunction. Arch Androl 1994;32:141-9.

12. Shafik A. Pudendal artery syndrome with erectile dysfunction: Treatment by pudendal canal decompression. Arch Androl 1995;34:83-94.

13. Klifto KM, Dellon AL. Neurolysis of the Dorsal Nerve to the Penis to Restore Function After Trauma. Ann Plast Surg 2020;84:307-11.

14. Erdogru T, Avci E, Akand M. Laparoscopic pudendal nerve decompression and transposition combined with omental flap protection of the nerve (Istanbul technique): technical description and feasibility analysis. Surg End 2014;925-32.

15. Basal S, Goktas S, Ergin A, et al. A Novel Treatment Modality in Patients with Premature Ejaculation Resistant to Conventional Methods: The Neuromodulation of Dorsal Penile Nerves by Pulsed Radiofrequency. J Androl 2010;31:126-30.

16. Luo K, Wang G, Tang W, et al. Effect of penile dorsal nerve neurotomy in patients with premature ejaculation. Available online: https://www.researchgate.net/ publication/291163888_Effect_of_penile_dorsal_nerve_ 
neurotomy_in_patients_with_premature_ejaculation

17. Shi WG, Wang XJ, Liang XQ, et al. Selective resection of the branches of the two dorsal penile nerves for primary premature ejaculation. Zhonghua Nan Ke Xue 2008;14:436-8.

18. Zhang WX, Shi YT, Wang R, et al. PE 08. Effect evaluation of penile dorsal nerve neurotomy in patients with premature ejaculation. Transl Androl Urol 2012. Available online: http://tau.amegroups.com/article/ view/384/435

19. Yong Z. Selective dorsal penile nerve rhizotomy joint preputial frenulum thread burial therapy for primary premature ejaculation in 330 patients. Journal of Xinxiang Medical College 2012.

20. Jian-hua L. Clinical observation of treatment of premature ejaculation by dorsal penile nerve amputation surgery combined with a-adrenergic receptor blocker. Medical Journal of the Chinese People's Armed Police Forces 2012.

21. Rapkin AJ, McDonald JS, Morgan M. Multilevel local anesthetic nerve blockade for the treatment of vulvar vestibulitis syndrome. Am J Obstet Gynecol 2008;198:41. e1-41.e5.

22. Vallinga MS, Spoelstra SK, Hemel ILM, et al. Transcutaneous Electrical Nerve Stimulation as an Additional Treatment for Women Suffering from Therapy-Resistant Provoked Vestibulodynia: A Feasibility Study. J Sex Med 2015;12:228-37.

23. Murina F, Bianco V, Radici G, et al. Transcutaneous electrical nerve stimulation to treat vestibulodynia: A randomised controlled trial. BJOG 2008;115:1165-70.

24. Murina F, Felice R, Di Francesco S, et al. Vaginal diazepam plus transcutaneous electrical nerve stimulation to treat vestibulodynia: A randomized controlled trial. Eur J Obstet Gynecol Reprod Biol 2018;228:148-53.

25. Filler AG. Diagnosis and treatment of pudendal nerve entrapment syndrome subtypes: Imaging, injections, and minimal access surgery. Neurosurg Focus 2009;26:E9-14.

26. Furtmüller GJ, McKenna CA, Ebmer J, et al. Pudendal nerve 3-dimensional illustration gives insight into surgical approaches. Ann Plast Surg 2014;73:670-8.

27. Burnett AL, Tillman SL, Chang TS, et al. Immunohistochemical localization of nitric oxide synthase in the autonomic innervation of the human penis. J Urol 1993;150:73-6.

28. Clement P, Giuliano F. Physiology and Pharmacology of Ejaculation. Basic Clin Pharmacol Toxicol 2016;119 Suppl 3:18-25.
29. Diallo D, Zaitouna M, Alsaid B, et al. What is the origin of the arterial vascularization of the corpora cavernosa? A computer-assisted anatomic dissection study. J Anat 2013;223:489-94.

30. Azadzoi KM, Siroky MB. Neurologic Factors in Female Sexual Function and Dysfunction. Korean J Urol 2010;51:443-9.

31. Kaur J, Singh P. Pudendal Nerve Entrapment Syndrome. StatPearls: StatPearls Publishing, 2019.

32. Hibner M, Desai N, Robertson LJ, et al. Pudendal Neuralgia. J Minim Invasive Gynecol 2010;17:148-53.

33. Ramsden CE, McDaniel MC, Harmon RL, et al. Pudendal nerve entrapment as source of intractable perineal pain. Am J Phys Med Rehabil 2003;82:479-84.

34. Heinze K, Nehiba M, van Ophoven A. Nervuspudendus-Neuralgie infolge Gewalttrauma. Urologe 2012;51:1106-8.

35. Marcus-Braun N, Bourret A, Von Theobald P. Persistent pelvic pain following transvaginal mesh surgery: A cause for mesh removal. Eur J Obstet Gynecol Reprod Biol 2012;162:224-8.

36. Sancak EB, Avci E, Erdogru T. Pudendal neuralgia after pelvic surgery using mesh: Case reports and laparoscopic pudendal nerve decompression. Int J Urol 2016;23:797-800.

37. Sultan AH, Kamm MA, Hudson CN. Pudendal nerve damage during labour: prospective study before and after childbirth. Br J Obstet Gynaecol 1994;101:22-8.

38. Lien KC, Morgan DM, Delancey JOL, et al. Pudendal nerve stretch during vaginal birth: A $3 \mathrm{D}$ computer simulation. Am J Obstet Gynecol 2005;192:1669-76.

39. Leiblum SR, Nathan SG. Persistent sexual arousal syndrome: A newly discovered pattern of female sexuality. J Sex Marital Ther 2001;27:365-80.

40. Stevenson BJ, Köhler TS. First Reported Case of Isolated Persistent Genital Arousal Disorder in a Male. Case Rep Urol 2015;2015:465748.

41. Kruger THC, Hartmann U. A Case of Comorbid Persistent Genital Arousal Disorder and Premature Ejaculation: Killing Two Birds with One Stone. J Sex Marital Ther 2016;42:1-3.

42. Markos AR, Dinsmore W. Persistent genital arousal and restless genitalia: Sexual dysfunction or subtype of vulvodynia? Int J STD AIDS 2013;24:852-8.

43. Rosenbaum TY. Physical therapy treatment of persistent genital arousal disorder during pregnancy: A case report. J Sex Med 2010;7:1306-10.

44. Bedell S, Goldstein AT, Burrows L. A Periclitoral Mass as 
a Cause of Persistent Genital Arousal Disorder. J Sex Med 2014;11:136-9.

45. Klifto KM, Dellon AL. Persistent Genital Arousal Disorder: Review of Pertinent Peripheral Nerves. Sex Med Rev 2020;8:265-73.

46. Philippsohn S, Kruger THC. Persistent genital arousal disorder: Successful treatment with duloxetine and pregabalin in two cases. J Sex Med 2012;9:213-7.

47. Waldinger MD, Venema PL, Van Gils APG, et al. Stronger Evidence for Small Fiber Sensory Neuropathy in Restless Genital Syndrome: Two Case Reports in Males. J Sex Med 2011;8:325-30.

48. Irwin GM. Erectile Dysfunction. Prim Care 2019;46:249-55.

49. Nolan MW, Marolf AJ, Ehrhart EJ, et al. Pudendal nerve and internal pudendal artery damage may contribute to radiation-induced erectile dysfunction. Int J Radiat Oncol Biol Phys 2015;91:796-806.

50. Gupta BP, Murad MH, Clifton MM, et al. The Effect of Lifestyle Modification and Cardiovascular Risk Factor Reduction on Erectile Dysfunction: a systematic review and meta-analysis. Arch Intern Med 2011;171:1797-803.

51. Althof SE, Mcmahon CG, Waldinger MD, et al. An Update of the International Society of Sexual Medicine's Guidelines for the Diagnosis and Treatment of Premature Ejaculation (PE). J Sex Med 2014;11:1392-422.

52. Xia JD, Dai YT. Pathogenesis of premature ejaculation: a neurobiological approach. Zhonghua Nan Ke Xue

Cite this article as: Aoun F, Alkassis M, Tayeh GA, Chebel JA, Semaan A, Sarkis J, Mansour R, Mjaess G, Albisinni S, Absil F, Bollens R, Roumeguère T. Sexual dysfunction due to pudendal neuralgia: a systematic review. Transl Androl Urol 2021;10(6):2500-2511. doi: 10.21037/tau-21-13
2014;20:1131-5.

53. Shabsigh R. Diagnosing Premature Ejaculation : A Review. J Sex Med 2006;3:318-23.

54. Martin-Tuite P, Shindel AW. Management Options for Premature Ejaculation and Delayed Ejaculation in Men. Sex Med Rev 2020;8:473-85.

55. Sun S, Han L, Li Y, et al. The safety and efficacy of dorsal penile nerve block for premature ejaculation: A systematic review and meta-analysis. Medicine (Baltimore) 2019;98:e16479.

56. Bachmann GA, Rosen R, Arnold LD, et al. Chronic vulvar and other gynecologic pain: prevalence and characteristics in a self-reported survey. J Reprod Med 2006;51:3-9.

57. Harlow BL, Stewart EG. A population-based assessment of chronic unexplained vulvar pain: have we underestimated the prevalence of vulvodynia? J Am Med Womens Assoc (1972) 2003 Spring;58:82-8.

58. Alimi Y, Iwanaga J, Oskouian RJ, et al. The clinical anatomy of dyspareunia: A review. Clin Anat 2018;31:1013-7.

59. Sorensen J, Bautsita K, Lamvu G, et al. Evaluation and Treatment of Female Sexual Pain: A Clinical Review. Cureus 2018;10:e2379.

60. Bautrant E, Porta O, Murina F, et al. Provoked vulvar vestibulodynia: Epidemiology in Europe, physiopathology, consensus for first-line treatment and evaluation of second-line treatments. J Gynecol Obstet Hum Reprod 2019;48:685-8. 